\title{
Maternal riboflavin deficiency
}

INSERM

\section{Source}

INSERM. (1999). Orphanet: an online rare disease and orphan drug data base. Maternal riboflavin deficiency. ORPHA:411712

Maternal riboflavin deficiency is a rare, genetic disorder of metabolite absorption or transport characterized by persistently decreased riboflavin serum levels due to a primary genetic defect in the mother and which leads to clinical and biochemical findings consistent with a secondary, life-threatening, transient multiple acyl-CoA dehydrog enase deficiency (MADD) in the newborn. The mother usually presents hyperemesis gravidarum in the absence of other features of riboflavin deficiency, such as skin lesions, jaundice, pruritus, sore mucous membranes, visual disturbances. 